\title{
EMPODERAMENTO POLÍTICO DOS CIDADÃOS
}

\author{
MANUEL GONÇALVES BARBOSA ${ }^{*}$ \\ ORCID: https://orcid.org/0000-0002-8728-6667
}

RESUMO: O presente artigo, a partir de uma análise interpretativa dos processos de economização, de despolitização e de consequente estreitamento das finalidades da educação nas sociedades mais avançadas em termos de neoliberalização, tem como objetivo resgatar a necessidade de empoderamento político dos cidadãos através da escolarização em ordem a reagir a esses processos e ao modo desajustado como encaram a resolução de muitos problemas contemporâneos. $\mathrm{Na}$ sua estrutura organizativa contempla-se a análise da erosão do homo politicus sob o efeito da neoliberalização, o reducionismo das metas da educação, o empoderamento como telos da escolarização e algumas pautas curriculares que se afiguram necessárias a esse empoderamento a partir da instituição escolar, não esquecendo de equacionar, nos termos da metodologia analíticointerpretativa, tanto as possibilidades como as dificuldades que se colocam ao efetivo fortalecimento do poder dos cidadãos nos sistemas educativos, hoje sob forte pressão de agentes políticos internacionais neoliberais.

Palavras chave: Empoderamento. Cidadãos. Escolarização. Meta Educativa.

\section{POLITICAL EMPOWERMENT OF CITIZENS}

ABSTRACT:This article is based on an interpretative analysis of the processes of economization, depoliticization and consequent education's goals narrowing in the most advanced societies in terms of neoliberalization. It aims to rescue the need for political empowerment of citizens through schooling, in order to react to those processes and to the misadjusted way they face the resolution of many contemporary problems. Its organizational structure includes the analysis of the erosion of homo politicus under the effect of neoliberalization, the reductionism of the education goals, the empowerment as telos of schooling and some curricular guidelines that seem necessary to that empowerment from the school institution. Not forgetting to ponder, within the terms of the analytic-interpretative methodology, both the possibilities and the difficulties that are placed to the effective strengthening of the power of citizens in educational systems, that are nowadays under a strong pressure from neoliberal international political agents.

Keywords: Empowerment. Citizens. Schooling. Educational Goal.

'Universidade do Minho, Instituto de Educação, Braga, Portugal.

"Doutor em Educação. Professor no Instituto de Educação da Universidade do Minho-Portugal.

E-mail:<mbarbosa@ie.uminho.pt $>$. 


\section{INTRODUC̣̃̃O}

O sentimento generalizado, entre os cidadãos das democracias neoliberais, de que não há alternativa e de que «a política já não pode mudar as suas vidas» (STREECK, 2017, p. 72), parece querer dizer que o empoderamento político é irrealista e que o sistema educativo, nomeadamente na vertente escolar, faria melhor em se ocupar de coisas verdadeiramente sérias, úteis e respeitáveis, como a reconfiguração mercantilista da educação, a produção de capital humano para o mercado de trabalho ou a inculcação, nos educandosclientes, da racionalidade que hoje domina amplas esferas da existência humana nas sociedades do capitalismo avançado e não tão avançado, ou seja, a racionalidade característica do homo oeconomicus da era neoliberal global, empresarial e financeira, tal como se expressa, de maneira cambiante, no centro e nas periferias do "sistema-mundo vigente» (WALLERSTEIN, 2007, p. 27).

Dar o empoderamento político como fútil, inecessário e fora de contexto talvez seja precipitado, pois não só «a história não terminou» (AVENT, 2017, p. 22) como ainda há muitas batalhas políticas pela frente, e não é só a questão da redistribuição dos benefícios do crescimento, ou a problemática do trabalho nas dimensões de precariedade, flexibilidade e raridade, numa altura em que se avizinham grandes transformações tecnológicas no modo de realizar as atividades produtivas. São também questões relacionadas com a construção de sociedades culturalmente inclusivas e ambientalmente sustentáveis, quer devido à diasporização global das populações, quer devido às ameaças de catástrofe ecológica iminente, resultantes do aquecimento global e das alterações climáticas na perigosa «era do antropoceno» (BONNEUIL; FRESSOZ, 2013, p. 17).

Os problemas que assediam os cidadãos por estes dias, mais do que técnicos, e até científicos, são eminentemente políticos, não obstante nos quererem convencer do contrário onde reina o tecnocratismo e onde a despolitização, como um vírus silencioso, se infiltra nas nossas vidas. $\mathrm{O}$ empoderamento político, face à especificidade e à dimensão desses problemas, nunca é demais. Sendo pedagogicamente improvável nos contextos onde a educação se coloca ao serviço da «economização alargada de esferas, atividades e sujeitos previamente não econômicos» (BROWN, 2016, p. 38), não deixa por isso de ser necessário, e mesmo incontornável, como contributo para a formação de cidadãos empenhados, lúcida, crítica e ativamente na construção de futuros viáveis e sustentáveis, ou ainda, e não menos importante, 
na revitalização da democracia onde esta se torna exangue, de baixa intensidade e pobre na efetivação de direitos, liberdades e garantias.

A realização pedagógica do empoderamento político, junto de crianças, jovens e adultos, é um desafio e requer não só a sua justificação nas formações sociais onde a erosão do homo politicus se associa a um dramático estreitamento da educação (primeira secção do artigo), como precisa de ser situada e esclarecida no âmbito mais vasto do empoderamento como horizonte educativo (segunda secção). Depois desse afloramento temático, quanto mais não seja para colocar em perspectiva os usos contemporâneos da noção de empoderamento e a sua utilização em educação, já se afigura pertinente (terceira secção) delimitar, sobretudo para fins práticos, alguns alinhamentos curriculares de promoção do empoderamento durante a escolarização dos cidadãos. O que se pretende, nessa circunstância, não é prescrever um caminho ou traçar imperativamente uma direção, mas tão só assinalar alguns âmbitos de atuação para que o empoderamento político se torne efetivo nos contextos onde se vai perdendo a noção dos efeitos perniciosos da neoliberalização.

\section{«NO PASA NADA»? EROSÃO DO HOMO POLITICUS E ESTREITAMENTO DA EDUCAÇÃO}

Sob o efeito anestesiante do senso comum dominante, característico das formações sociais que no centro e nas periferias do sistema-mundo capitalista se regem por crenças neoliberais, como é o caso de muitos países da OCDE, designadamente os da região euroatlântica, parece que nada acontece de verdadeiramente significativo, quer em termos mais especificamente antropológicos, ou no que tem a ver com a representação/simbolização do ser humano, quer em termos pedagógicos ou educacionais, no que se refere às metas, aos propósitos ou às finalidades da educação.

Operando nesses contextos como «tecnologia de conformação e de hegemonia de carácter difuso» (LOUÇÃ; LOPES; COSTA, 2014, p. 336), e servindo-se fundamentalmente das redes mediáticas existentes, desde as tradicionais às digitais, esse senso comum neoliberal faz-nos acreditar, sob a força performativa dos discursos empresariais que lhe dão corpo e espessura, que tudo ocorre de forma natural e que nada se passa quando o homo politicus perde importância para o homo oeconomicus e a educação, ela própria contribuindo para essa mudança de perspectiva, se torna «uma educação guiada pelos mercados» (CHOMSKY; POLYCHRONIOU, 2017, p. 187) isto é, 
uma educação com fins economicistas, ávida de lucro, e seguidista das injunções que lhe chegam dos atores hoje em dia mais influentes na reorientação das políticas educativas, entre os quais as grandes corporações empresariais e as entidades que, dando voz e amplificação às pretensões dessas corporações do mundo dos negócios, se assumem como as «vozes autorizadas para falar com propriedade e rigor suficiente sobre os temas e os problemas educativos» (TORRES SANTOMÉ, 2017, p. 67), como é notoriamente o caso da OCDE, FMI e Banco Mundial, através de relatórios, dados estatísticos, comparações internacionais e abundantes recomendações.

O que se evidencia nessa complexa fenomenologia, e que já aflora em práticas e discursos correntes é, por um lado, a erosão da representação do serhumano mais além do econômico, o que, nos termos um pouco exagerados de Wendy Brown (2016, p. 145) corresponde a uma «derrota do homo politicus às mãos do homo oeconomicus, e, por outro, o dramático estreitamento da educação enquanto projeto humanista de formação integral do ser humano, reduzindo-a à construção de subjetividades demandadas pelo mercado de trabalho segundo a lógica do treino laboral rentável, competitivo, flexível e adaptável, de modo que o investimento resulte em capital humano altamente posicionado e valorizado por esse mercado volátil, extremamente incerto e em convulsão permanente na era de um turbocapitalismo cada vez mais apostado em inovações disruptivas e lucrativas.

Essa visão do ser humano, e da própria educação, à base da acentuação de aspetos econômicos, laborais e instrumentais, e não propriamente segundo preocupações de ordem política, como poderia acontecer na representação e na formação de um sujeito interventivo na governação do que é comum, do que é de todos, não tem nada de estranho ou extraordinário, pois resulta da racionalidade que, nas sociedades neoliberalizadas, «dissemina os valores e as métricas do mercado em cada esfera da vida e que interpreta o ser humano exclusivamente como homo oeconomicus» (2016, p. 236), isto é, e de acordo com uma versão que incorpore quer notas distintivas clássicas quer aspetos mais atuais, como ser ou individualidade que tudo reduz a mercadoria, que se move pela acumulação de riqueza, pela avidez do lucro, e que se vê como sujeito empreendedor, não apenas na maximização de proveitos pessoais, em bens e serviços, no quadro de relações instrumentais e competitivas entre indivíduos, como também na melhoria do seu valor de mercado, na sua cotação, investindo em si mesmo, adquirindo ou comprando qualificações, ganhando prestígio e subindo ao topo das hierarquias do poder, da riqueza e do 
reconhecimento, ainda que isso implique, como um bom «empresário de si mesmo» (FOUCAULT, 2004, p. 232), deixar para trás todos os outros e não respeitar princípios e valores de companheirismo, relação empática, solidariedade, entreajuda e altruísmo.

O fenômeno da neoliberalização, no âmbito do qual se constitui essa imagem do homo oeconomicus e essa minguada concepção de educação, é essencialmente um processo de «economização» (CALISKAN; CALLON, 2009, p. 370) da vida humana e bem assim das esferas onde se desenvolve, como a vida doméstica, a política, os cuidados sanitários, a justiça ou a educação, e não tem que implicar, necessariamente, monetarização. Como nos diz Wendy Brown (2016, p. 35-36) a esse propósito:

É importante destacar que essa economização nem sempre envolve monetarização [...]. Falar da implacável e ubíqua economização de todas as características da vida pelo neoliberalismo, portanto, não implica afirmar que o neoliberalismo, literalmente, mercantiliza todas as esferas, ainda que esta mercantilização seja sem dúvida um importante efeito do neoliberalismo.

A economização, estendendo-se ao sujeito, à sua vida, à sua conduta, ao seu modo de ser e de estar, de fazer e realizar, opera a reconversão antropológica do ser humano em ator econômico e em capital humano, cuja preocupação é cada vez mais o fortalecimento do seu posicionamento competitivo no mercado, assim se preparando para a «guerra da competição» num mundo de «frenesim competitivo» (BAUMAN, 2017, p. 50).

Essa economização do sujeito, segundo Wendy Brown (2016, p. 40-41), é contemporaneamente peculiar pelo menos em três notas ou aspetos:

Primeiro, em comparação com o liberalismo clássico, somos homo oeconomicuse somente homo oeconomicus- em todo o lado [...]. Segundo, o bomo oeconomicus neoliberal toma a forma de capital humano para fortalecer a sua posição competitiva e aprecia o seu valor como figura intercambiável [...]. Terceiro, e relacionado com isso, atualmente o modelo específico para o capital humano e suas esferas de atividade é cada vez mais o capital financeiro ou de investimento e não apenas o capital produtivo ou empresarial.

Nessas condições, a «capitalização de si» (MBEMBE, 2017, p. 236) é sem dúvida a melhor opção para sobreviver na selva da competição, das lutas por benefícios, lucros e rendimentos, até porque o indivíduo, sem a almofada protetora de políticas sociais generosas, é que tem de tratar de si mesmo, de garantir segurança, bem-estar e meios de sobrevivência, fazendo valer o seu portfólio de 
competências empreendedoras, que é o que se espera que a educação promova ao longo e ao largo da vida, seguindo os ditados dos agentes e das agências que zelam pela reconfiguração empresarial e financeira dos sistemas educativos, do ensino e da escola, à base de estudos de grande alcance, como o PISA da OCDE, supostamente a verdade objetiva, e indiscutível, da qualidade da educação.

A onda de economização que está varrendo as sociedades neoliberalizadas, ao atingir o próprio sujeito, exerce uma forte pressão no sentido de sua despolitização e tudo o que lhe diz diretamente respeito: satisfação de necessidades, emprego/desemprego, redistribuição de riqueza, relações sociais, educação, aposentadoria, cuidados sanitários, e outras áreas que contribuem para o seu bem-estar ou mal-estar. O que se diz ao neo-sujeito, à subjetividade neoliberal, é que tudo isso tem um preço e que o foco da vida, a sua inultrapassável prioridade, reside no tratamento econômico, de maneira individual e privatista, desses assuntos. «É óbvio», como assinalam acertadamente Fernández Liria, García Fernández e Galindo Ferrández (2017, p. 218), «que uma abordagem como essa procura desativar qualquer iniciativa que tenha um caráter político ou reivindicativo».

A reconstrução dos sujeitos à luz da implacável economização neoliberal, ao retirar-lhes substância política, sobretudo através do poder brando do consentimento e do convencimento, da cultura ambiente saturada de mensagens individualistas e mercantilistas, das práticas institucionais e das políticas sociais, ainda que fortemente encolhidas nos contextos de neoliberalização mais desenvolvida ou avançada, contribui decisivamente para fazer deles meros «cidadãos de mercados» (NACHTWEY, 2017, p. 211) cujo ângulo de visão não vai além dos limites do próprio ego. Assim, transformam facilmente problemas sociais em questões individuais, como o desemprego de massas, a pobreza, a precariedade laboral ou as exclusões sociais, e subtraem responsabilidade às políticas e aos políticos que interferem no desenho, gestão e condução das suas vidas.

O sujeito despolitizado da nova ordem neoliberal, ressalvando especificidades locais e diferentes graus de intensidade, «aborda tudo como um mercado e só conhece o comportamento de mercado; não pode pensar os propósitos públicos ou os problemas comuns de maneira claramente política» (BROWN, 2016, p. 48). Por conseguinte, não se pode ver como membro de um demos que afirma a sua ação política perante problemas sistêmicos, de grande envergadura, e que só decisões coletivas, de caráter estruturante, podem conter, mitigar ou debelar, dentro das possibilidades ainda existentes a nível nacional 
e/ou regional, apesar desse preocupante «divórcio entre poder e política» (BAUMAN, 2017, p. 50), seguramente limitativo da soberania dos povos quando se confrontam com problemas sedimentados nas suas formações sociais desde há longa data.

Uma das consequências mais perturbadoras dessa despolitização dos sujeitos, e que nos deveria interrogar enquanto educadores profissionais, reside no fato das subjetividades neoliberais, objeto de economização intensiva, já não usarem, de maneira audível, a «linguagem política de justiça» (BROWN, 2016, p. 150), essencial para reivindicar uma vida decente e digna sob o «capitalismo predatório» (CHOMSKY; POLYCHRONIOU, 2017, 96), criador de profundas assimetrias e desigualdades. O que se afirma, pelo contrário, e sem complexos, é uma linguagem econômica de investimento, de rentabilidade, de empreendedorismo, numa palavra, de mercado. Ora, desse modo, o bomo politicus só pode definhar e, com ele, as lutas e as reivindicações por uma sociedade melhor.

O que se verifica é que a educação, sendo conivente com a agenda da neoliberalização, pelo menos em alguns dos seus tópicos, não está servindo de dique, barreira ou tampão a essa despolitização dos cidadãos:

Estamos a permitir, via reformas educativas que se têm promovido nas últimas décadas, uma educação ao serviço de uma intensa despolitização, claramente individualista, com a qual se trata de isolar cada estudante-cidadão, e incapacitá-lo para se ver em comunidade, e como corresponsável do presente e do futuro da sua comunidade (TORRES SANTOMÉ, 2017, p. 136).

A isso, acresce nomeadamente nos contextos onde mais se fazem sentir as investidas do homo oeconomicus sobre o homo politicus, a passividade da educação face à descredibilização de tudo o que seja prática política, como se a política não fosse essencial à «criação e à regulação da ordem social» (STREECK, 2017, p. 136), não obstante as limitações impostas pelos avanços consolidados da globalização, sobretudo econômico-financeiros, e por uma certa desterritorialização do poder relativamente à política.

Mesmo sob condições adversas e extremamente desfavoráveis, comoéseguramenteo casonos contextos democráticos neoliberalizados, ou em vias de se tornarem sociedades neoliberais, a educação não tem que ser complacente com essa despolitização, seja no sentido de limitação do horizonte comunitário dos cidadãos, e de correspondente incapacitação para articularem as suas preocupações com as de outros cidadãos, seja no sentido de anatematização da atividade política, como se a política tivesse que ser, sempre e em todo o lado, atividade suja, feia e indigna, ao serviço de grupos predatórios. 
A educação, através de educadores e professores explorando espaços de manobra e linhas de fuga nos mapas curriculares escolares, ou até mesmo extracurriculares, pode ajudar a evitar o pesadelo de formações sociais integralmente neoliberais, subjugadas à impiedosa lógica dos mercados, ao despotismo do homo oeconomicus e à cegueira do apoliticismo em questões tanto vitais como estruturais, se tiver a ousadia, ou simplesmente a coragem, de se implicar, com maestria, no empoderamento dos cidadãos. Ora, e como condição prévia, isso envolve trazer à discussão o empoderamento como orientação da educação.

\section{O EMPODERAMENTO COMO HORIZONTE EDUCATIVO}

A educação, além de proporcionar saber, e não só nas modalidades formais do seu acontecer institucional, também dá poder, ou melhor, também permite que as pessoas se tornem poderosas, mais capazes de darem forma às suas vidas e de influírem, significativamente, nas forças que condicionam as suas ações, as suas trajetórias, as suas opções. Assim entendida, e não há razões para se pensar o contrário, pelo menos em contextos democráticos, inclusive neoliberalizados, a educação é uma via de empoderamento, um instrumento ao serviço do acréscimo de poder dos sujeitos, poder que tanto pode ser usado para se conformar ao sistema vigente, para nele se inserir e nele aproveitar as oportunidades disponíveis, como pode ser utilizado para criticar e transformar esse sistema, as suas prescrições, as suas normas, o seu regime de integração social e bem assim os seus procedimentos rotineiros, habituais, de modelagem das subjetividades.

Enquanto acréscimo de poder, ou «mais poder» (PINTO, 2013, p. 51), como diz seu significado literal, o empoderamento (do inglês empowerment) é ambíguo, vacilante, indeciso, requerendo, por isso mesmo, uma clarificação de sentido, especialmente quando está em causa a sua colocação no horizonte finalístico da educação, isto é, no endereço final, derradeiro, das ações que dão sentido ou significado às práticas educativas.

Não é suficiente dizer, portanto, que a educação é uma via de empoderamento e que até ocupa um lugar de destaque nesse processo, como facilmente se pode admitir dada a relevância da educação na produção de subjetividades. Importa, pois, determinar que empoderamento é visado pela educação. Melhor: que alternativas se colocam à educação em sua missão de empoderamento dos atores sociais. Essa é uma tarefa incontornável, não apenas para um esclarecimento de noções, conceitos ou representações, como 
também para delinear os referenciais teóricos de ações possíveis no terreno das práticas educativas, designadamente escolares ou formalmente institucionalizadas nas escolas.

A orientação da educação para o empoderamento, ou a inscrição deste último nas suas metas ou finalidades, não diminui, antes acrescenta politicidade à educação, pois o empoderamento, cuja raiz é o poder, «é um conceito sociopolítico» (DIGHE, 1995, p. 42) com múltiplas conotações ideológicas, umas mais na linha das ideias feministas que impuseram o empoderamento nas agendas do desenvolvimento (CALVES, 2009, p. 738) e numa série de lutas contra a violência de gênero (BACQUÉ; BIEWENER, 2013, p. 7-8) entre os anos 1970 e 1980, e outras mais sintonizadas com «as apropriações oportunistas» (PEREIRA, 2008, p. 14) dessas mesmas ideias, isto é, com as ressignificações neoliberais do empoderamento. Se estas últimas advogam a integração no status quo e a sua reprodução através de adaptação, já as primeiras, imbuídas de pensamento democrático genuíno e radical, suscitam o questionamento da ordem social vigente, nomeadamente as assimetrias de poder, as injustiças e as desigualdades de oportunidades, e apelam à sua transformação no sentido de possibilitar, ou de abrir perspectivas, à emancipação de indivíduos, grupos e coletividades, especialmente os que se incluem na categoria dos have not, isto é, dos sem-poder, dos subalternos, dos marginalizados, dos excluídos e dos irrelevantes, tanto para o processo de geração, acumulação e reprodução de capital, como para a tomada de decisões estratégicas e prospectivas relativamente à direção ou à condução da sociedade.

É certamente possível identificar, e retratar, na rica fenomenologia social contemporânea do sistema-mundo, posições atenuadas, mais ou menos soft, dessas duas concepções de empoderamento e, consequentemente, de educação para o empoderamento. Não rejeitando essa possibilidade, de resto já explorada por outros autores (BACQUÉ; BIEWENER, 2013), reconhecemos, no entanto, que as vantagens que daí resultam não compensam, manifestamente, o que se perde em clareza política, sobretudo quando se equaciona a relação ou o entrosamento da educação com o empoderamento político e quando está em causa um bom discernimento nessa matéria, seja na demarcação teórica de conceitos, seja na evidenciação de consequências com real impacto nas práticas pedagógicas.

Os tipos puros, a esse respeito, são mais esclarecedores, podendo ser usados, heuristicamente e com parcimônia, para circunscrever as assunções de empoderamento presentemente em disputa: por um lado, o empoderamento funcionalista, adaptativo 
e reprodutor, um empoderamento que hoje se poderia considerar mainstream, tal é a sua repercussão epistêmica na modelagem de discursos sobre o fortalecimento do poder dos indivíduos em contextos sociais neoliberais, ou em vias de incorporarem as perspectivas da neoliberalização sob o efeito da atual globalização, e, por outro, o empoderamento crítico, emancipatório e transformador, um empoderamento contra-hegemônico que se inspira nas teorias progressistas de transformação social, nomeadamente na de Paulo Freire (1975), e nas práticas feministas de oposição a tudo o que seja discriminação das mulheres em arenas econômicas, profissionais, sociais, domésticas, culturais e políticas.

O que cabe no registro de cada tipo de empoderamento, e que é decisivo para a educação, é-nos sugerido pela respectiva adjetivação. Relativamente ao que mais se destaca no senso comum dominante, ou que colhe as preferências da governamentalidade neoliberal, o empoderamento é um projeto, certamente focalizado no reforço dos poderes ou capacidades do sujeito, mas, estando apenas interessado nos átomos sociais, isto é, nos indivíduos, não tem senão a ambição de os tornar funcionais à lógica dos mercados e, portanto, à lógica do sistema econômico-social que espera deles a força, a destreza e as demais «virtudes» do homo oeconomicus, tanto em termos produtivos, empresariais, como em termos financeiros ou de investimento. Os indivíduos são empoderados para triunfarem nos mercados e para serem, ao longo e ao largo da vida, empresários de si mesmos, empreendedores e cuidadores de si mesmos, ou não fossem eles, segundo a ideologia inspiradora desse empoderamento, os únicos responsáveis pela sua situação, por tudo o que de bom ou de mau pode ocorrer no decurso de uma existência: inserção na vida ativa, permanência no posto de trabalho, condição laboral precária, vulnerabilidade social, queda na exclusão e na marginalidade, sucesso e insucesso nos estudos, posicionamento no sistema da desigualdade, riqueza e pobreza, reconhecimento e discriminação.

Denotando estreiteza de vistas e priorizando, estrategicamente, tudo o que possa contribuir para o fortalecimento da capacidade de «self-help» (BACQUÉ; BIEWENER, 2013, p. 45), isto é, de autoajuda, de socorro de si mesmo, com esse empoderamento o que se espera é que os sujeitos, reforçados na sua capacidade de agir, ou no seu «poder de agin», como prefere Le Bossé (2003, p. 45), se adaptem às condições e às estruturas existentes na sociedade $\mathrm{e}$ saiam vencedores da competição com os iguais, não necessariamente em oportunidades, pois essas são escandalosamente assimétricas 
(TORRES SANTOMÉ, 2017, p. 83) quando ainda se discrimina em função da classe socioeconômica, do sexo, do gênero, da raça ou da etnia, mas iguais em responsabilidade individual, em dedicação, em esforço, em compromisso, em trabalho duro, em eficácia, em rendimento, em empreendedorismo.

Nesse sentido, o empoderamento é para reproduzir a ordem vigentee para legitimar a concentração de responsabilidades no indivíduo. Eventuais falhas nas esferas sociais, políticas e econômicas reduzemse às falhas pessoais, às deficiências de caráter ou de personalidade, e devem ser colmatadas, ou simplesmente mitigadas, pelo indivíduo empoderado, isto é, reforçado em destrezas competitivas para ser bemsucedido nos mercados, nas arenas onde supostamente se resolvem todos os problemas, onde se satisfazem desejos e necessidades. Assim, vê-se a economização estender-se à compreensão do empoderamento e assiste-se, consequentemente, à sua despolitização. Depois dessa operação já não é possível associar o empoderamento com a educação política dos cidadãos, pelo menos de maneira honesta, frontal e aberta, e muito menos com um projeto de transformação dos sistemas onde se desenvolvem as existências das pessoas.

Desde posições subalternas, e seguramente com menos eco no espaço público de múltiplas configurações sociais, especialmente neoliberais, afirma-se, no entanto, um tipo de empoderamento que se distancia do individualismo, do economicismo e do reprodutivismo do anterior, podendo ser designado, para efeitos de categorização, como sendo um empoderamento crítico, emancipatório e transformador, assente na consciência das assimetrias e das desigualdades na distribuição do poder e dos recursos, e abrangendo dimensões individuais, sociais e políticas, tal como decorre, historicamente (CALVÉS, 2009, p. 737), das primeiras teorias do empoderamento elaboradas em solo norte-americano.

O empoderamento, segundo essa outra perspectiva, é simultaneamente um processo individual e coletivo cuja meta ou objetivo é ajudar os sujeitos a conduzirem as suas vidas e também a emanciparem-se, sendo necessário, nesse sentido, a realização de um processo ou dinâmica de conscientização, visando, como decorre da inspiração freiriana, a organização da transformação do «status da realidade» (FREIRE, 1980, p. 69) em diferentes áreas ou esferas. Essa visão de empoderamento, genuinamente democrática, visa permitir aos indivíduos e aos grupos aumentar o seu poder de agir e bem assim o desenvolvimento de destrezas ou competências que os tornem influentes nas tomadas de decisões que afetam as suas 
vidas, os seus ambientes, as suas relações. Por isso mesmo, não só se reforça a consciência crítica das situações, do mundo vivido, como se potencia o engajamento social e político na transformação desse mundo, dos seus processos, das suas estruturas.

O empoderamento crítico, emancipatório e transformador, olhando desse modo para os atores sociais, especialmente os que pertencem às camadas mais feridas da sociedade (FRIEDMAN, 1996, p. 112), articula três dimensões: a dimensão individual ou interior, designando o processo que permite a cada indivíduo desenvolver uma consciência crítica e a sua capacidade de agir, implicando, por essa razão, a construção de uma imagem positiva de si e a aquisição de saberes e competências que favoreçam a compreensão crítica do meio, o seu desvelamento crítico, e o desenvolvimento do pensamento estratégico e da «capacidade à aspiração» (APPADURAI, 2013, p. 237), ambos necessários à prossecução de objetivos pessoais e coletivos; a dimensão interpessoal, organizacional ou coletiva, designando a ativação ou o desenvolvimento da capacidade de agir cooperativamente nas arenas do espaço público, e, por fim, a dimensão política ou social, a qual coloca a questão da transformação da sociedade e a emancipação dos indivíduos em espaços politicamente assimétricos, injustos, opressivos, discriminatórios e antidemocráticos.

A essa luz, e tomando em consideração as várias dimensões referidas, o empoderamento pode ser um interessante horizonte da educação, possibilitando, quando devidamente trabalhado na prática, o fortalecimento político dos cidadãos e uma abordagem, sem cinismos, desvios e mistificações, de várias questões e problemas candentes.

\section{APROXIMANDO A META DO EMPODERAMENTO POLÍTICO: ALGUMAS PAUTAS CURRICULARES}

Ao associar a educação ao empoderamento político dos cidadãos, designadamente na escola, e sobretudo por isso, devemos «estar criticamente conscientes dos limites da educação» e que é ilusório «esperar que ela vá realizar a grande transformação social» (FREIRE; SHOR, 1987, p. 82). Ainda assim, e enquanto escolarização, a educação tem certamente um papel a jogar na promoção desse empoderamento, reforçando, ao longo de diversos ciclos de estudos e em diferentes disciplinas curriculares, poderes ou capacidades sem os quais dificilmente haverá limitação dos efeitos perniciosos da neoliberalização e alguma esperança em afrontar as crescentes desigualdades sociais, o capitalismo predatório e a própria crise das democracias, para já não falar em questões mais sistêmicas e globais, como a dos «Estranhos 
que nos batem à porta» (BAUMAN, 2016) na sequência de grandes movimentos populacionais através das fronteiras de várias nações, ou até «A metamorfose do mundo» (BECK, 2017) resultante das alterações climáticas e do aquecimento global, sinalizando esta última aquela que parece ser a maior ameaça ao nosso planeta.

A ação política na sociedade, tanto à escala reduzida do Estadonação como no âmbito mais alargado da sociedade planetária, ou em espaços políticos intermédios, é deveras importante para fazer face a todos esses problemas, mas pouco se adiantará se não se investe no empoderamento político dos cidadãos, na sua capacitação para essa ação.

A escolarização de crianças, jovens e adultos tem aí um espaço de intervenção, mas não tem que seguir, mimeticamente e em todo o lado, o mesmo padrão curricular. Os sistemas educativos, apesar das pressões uniformizadoras de instâncias internacionais, como a OCDE, o Fundo Monetário Internacional e o Banco Mundial (TORRES SANTOMÉ, 2017, p. 157), não são todos iguais e o empoderamento político, para não se tornar um corpo estranho nos contextos de implantação ou de enraizamento, deve adaptar-se às especificidades locais e tirar partido das suas idiossincrasias em termos educacionais. Ainda assim, algumas pautas curriculares similares podem fazer parte desse empoderamento em meio escolar, quer onde existam disciplinas de educação para a cidadania, ou componentes curriculares desse tipo, quer em disciplinas de ciências sociais e de humanidades, apesar do pouco peso que possam ter na avaliação sumativa dos alunos, ou na preparação para exames e «provas-PISA», isto é, provas promovidas pelo Programme for International Student Assessment (Programa Internacional de Avaliação de Alunos) da Organização de Cooperação e de Desenvolvimento Económico (OCDE).

$\mathrm{O}$ que se espera, com novos alinhamentos curriculares, e de forma necessariamente gradativa ao longo do ciclo escolar, pois tudo tem que ser feito com peso e medida em função da faixa etária com que trabalha o professor, é que os alunos, robustecidos em poder ou capacidade de análise, argumentação, comunicação e participação, se tornem mais efetivos no exercício de sua cidadania e, portanto, mais influentes no condicionamento das decisões que afetam as suas vidas em termos econômicos, sociais, culturais e ambientais, quer como pessoas singulares em busca de autorrealização, quer enquanto membros de comunidades aspirando a modos de vida mais democráticos, justos, solidários, inclusivos, decentes e sustentáveis. Essa forma de ver o empoderamento político dos cidadãos, ou em vias de o serem plenamente, já sinaliza os poderes ou capacidades que se afigura necessário fortalecer ou reforçar no âmbito das instituições escolares. 
Antes de mais, e como primeira pauta, o robustecimento da capacidade de análise do meio social em termos políticos, chamando a atenção, nomeadamente a partir de estudos desse meio, os quais podem ser protagonizados pelos alunos, para o caráter político, quer dizer, fruto de uma decisão, dos mais variados aspetos da vida em sociedade, como podem ser a maior ou menor democraticidade da estrutura de oportunidades, as relações de poder entre classes, raças, sexos e gêneros, a integração ou a rejeição de migrantes e refugiados, os constrangimentos estruturais que mantêm os pobres na pobreza e na indigência, ou a exclusão do processo político por não se resolverem problemas básicos de subsistência.

O que se pretende, por essa via, é desenvolver a consciência social e política dos alunos, hoje tão desatendida pelos currículos economicistas e mercantilistas (TORRES SANTOMÉ, 2017, p. 132) de um neoliberalismo sem freio, reconfigurador dos sistemas educativos em função das necessidades do mercado de trabalho, isto é, ajustando-os às necessidades das empresas (FERNÁNDEZ LIRIA; GARCÍA FERNÁNDEZ; GALINDO FERRÁNDEZ, 2017, p. 218) e não propriamente às aspirações das pessoas, dos cidadãos, ou sequer à preparação de uma «cidadania democrática inteligente» (BROWN, 2016, p. 238) capaz de deslindar, desde os bancos da escola, e tão cedo quanto possível, que não há «soluções biográficas para problemas sistémicos» (BECK; BECK-GERNSHEIM, 2003, p. 31), ou seja, «soluções individuais para problemas socialmente produzidos» (BAUMAN, 2009, p. 109), como, por exemplo, o desemprego de massas, a precariedade laboral, a pobreza extrema ou a insensível destruição dos ecossistemas pelas atividades econômicas predatórias.

A esse reforço do poder de visão inteligente do meio social, sobretudo em termos políticos, que é o que vai faltando ao cidadão dos contextos sociais neoliberais, acrescenta-se, como segunda pauta curricular, a potenciação da capacidade de argumentação, indispensável para se ter voz impactante nas arenas onde se tomam decisões públicas e, consequentemente, onde se desenham políticas para o presente e o futuro dos cidadãos. É pela discussão de temas sociais polêmicos, e no respeito pelas convicções de cada um, que essa capacidade se fortalece, sendo necessário, para o efeito, começar por investigar esses temas, ajudar a discernir as suas facetas, as suas dimensões, as suas arestas, e na sequência organizar debates em que a preocupação primeira, fundamental, seja dar substância, conteúdo e criticidade à assunção de ideias, posições e argumentos.

Uma forma de tornar esse trabalho pedagógico simultaneamente mais atrativo e produtivo, quer pensando na motivação em sala de 
aula, quer equacionando a aquisição de ferramentas comunicacionais digitais, consiste em recorrer a materiais audiovisuais disponibilizados nas plataformas de revistas e jornais on-line, seja para melhor informar os debates sobre questões sociais de especial interesse para os cidadãos, como é o caso da «insegurança existencial» (BAUMAN, 2016, p. 31) que afeta particularmente, e com evidente dramaticidade, os segmentos mais fustigados pelas políticas neoliberais dominantes, seja para fazer letramento digital em contexto formal e, assim, alavancar o que podemos designar, na continuidade de Phillippi e Avendaño (2011), empoderamento comunicacional digital dos alunos, essencial, na era do uso intensivo da Internet como nova ágora de cidadania, para veicular e discutir narrativas sobre temas e problemas comuns, para endereçar reivindicações aos centros de decisão política, fazer pressão, organizar campanhas e desencadear movimentos sociais em torno de causas públicas.

Sobre uma base de letramento digital, ou «alfabetização digital» (ORTOLL, 2007, p. 13), mais dirigido ao conhecimento e ao domínio dos dispositivos tecnológicos de acesso e navegação na web, há toda uma área de comunicação digital que pode ser explorada e reforçada na escola, seja experimentando novos códigos e novas gramáticas de narração da realidade, de questões e preocupações dos cidadãos, e antes de mais dos alunos, seja descobrindo as potencialidades da utilização desses códigos, dessas gramáticas, em práticas de ativismo digital e, portanto, de «e-cidadania», nesse vastíssimo território da « Galáxia Internet» (CASTELLS, 2001) onde se destacam, pelo seu especial significado para essas práticas de cibercidadania, as conhecidas, usadas e propaladas redes sociais.

A comunicação digital é hoje um importante veículo de expressão política dos cidadãos, um meio para a sua afirmação nas arenas onde se tomam decisões, sendo necessária, aos mais diversos níveis, para condicionar as forças que dão forma à sociedade e desenham o seu futuro. A voz política dos cidadãos, sem amplificação digital, corre o risco de se tornar inaudível, de passar despercebida, de pouco ou nada valer para desafiar, intelectual e ideologicamente, o discurso dominante, as suas narrativas, as suas injunções e as suas ficções, como a do homo oeconomicus autossuficiente, egoísta e individualista, único «responsável pelos seus êxitos e pelos seus fracassos»(TORRES SANTOMÉ, 2017, p. 84), sem dívidas relativamente aos demais, como, por exemplo, a sua comunidade de pertença; um sujeito ou um «tipo humano orientado pela racionalidade do lucro e que, como empresário de si mesmo, considera "irracional" qualquer gesto de altruísmo ou fraternidade» (FERNÁNDEZ LIRIA; GARCÍA FERNÁNDEZ; GALINDO FERRÁNDEZ, 2017, p. 34). 
O contributo que a escolarização pode dar ao empoderamento político dos alunos também passa pela comunicação digital, pela sua potenciação através da utilização, em sala de aula, das novas tecnologias de informação e comunicação, não apenas de maneira tangencial, como pode ocorrer em qualquer disciplina curricular, mas também de modo direto e intencional no quadro do tratamento de assuntos de cidadania, e de implicação na vida pública, em disciplinas correspondentes do plano de estudos da instituição escolar.

A essa potenciação da comunicação digital seguir-se-ia, em termos de empoderamento político, o desenvolvimento da capacidade de participação dos alunos nos assuntos comuns, nos assuntos da coletividade, pois não há empoderamento digno desse nome que não ajude a consumar, desde o meio escolar, a «vocação ontológica de intervir no mundo» (FREIRE, 1996, p. 54), de o transformar e mudar, de o tornar menos arestoso, de evitar que se converta em realidade feia, desagradável, inóspita, como acaba por fazer a sua reconfiguração economicista e mercantilista nos países onde $\mathrm{o}$ «mercado continua a ser a medida de referência para todas as esferas da vida» (NACHTWEY, 2017, p. 210), onde se aceita que não há outro horizonte político a não ser o neoliberalismo.

A participação, «como capacidade de trabalhar em equipa de conviver e cooperar com os outros para melhorar o meio e alcançar metas comuns» (VENTOSA, 2016, p. 99) não desponta, nem naturalmente nem isoladamente, e não ocorre repentinamente, da noite para o dia. O seu robustecimento é gradual, requer um grupo colaborativo, exige ação (aprende-se a participar participando) e precisa do apoio e do estímulo do professor, nomeadamente no lançamento, definição, implementação e avaliação de projetos de cidadania, preferentemente em interação com a comunidade local, como é recomendado pela «aprendizagem-serviço» (MARTÍN; RUBIO, 2010), uma metodologia que, em contexto escolar, e segundo alguns dos estudos apresentados na obra coordenada por esses autores, parece dar bons resultados no desenvolvimento da competência participativa dos alunos e, consequentemente, do seu empoderamento político nessa importante dimensão.

Devemos reconhecer que não é fácil preencher todos esses requisitos, especialmente quando está em questão a colaboração e o envolvimento dos alunos em projetos de intervenção na sociedade, não apenas porque são encorajados, desde o senso comum dominante, a tratarem de si mesmos, a serem individualistas e competitivos, no sentido mais frio e agressivo desses termos, mas também a acomodarem-se ao statu quão por, supostamente, não haver alternativa 
à ordem vigente, ao sistema que impõe em todo o lado, sem reservas, complexos e estados de alma, a lei férrea dos mercados.

Será isso razão suficiente para não se investir, desde a instituição escolar, no reforço do poder de intervir no mundo por parte dos alunos? Quando o objetivo é o seu empoderamento político, esse reforço é inevitável, é uma pauta curricular a levar em linha de conta, como de resto todas as que foram sinalizadas para promover, ao longo da escolarização, e em momentos-chave, essa importante meta da educação.

\section{CONSIDERACִ̃̃ES FINAIS}

Como decorre da trama analítico-interpretativa deste artigo e dos seus principais argumentos, as condições e as possibilidades de empoderamento político, quer para a educação em geral, quer para a escolarização em particular, não são propriamente as melhores nos países da neoliberalização avançada, isto é, nos estados territoriais onde mais intensamente se faz sentir a economização das esferas da vida e, por arrastamento, a sua despolitização. O lema parece ser «economizar para despolitizar e despolitizar para economizar» por forma a refazer, nessas esferas e nesses contextos, toda a paisagem social. Quando a educação e a escola, sob a pressão de políticas educativas neoliberais, não conseguem romper com esse círculo vicioso, a situação para o empoderamento político ainda se torna mais difícil.

Nesse caso, só explorando oportunidades e linhas de fuga, nomeadamente em disciplinas de educação para a cidadania, para os direitos humanos e, até, em unidades curriculares das ciências sociais, de estudo do meio e das humanidades, se poderá incentivar e fornecer um significativo contributo a essa modalidade de empoderamento, salvaguardando, necessariamente, as especificidades de cada contexto, quanto mais não seja porque se assiste, desde há algum tempo, a um «desenvolvimento geográfico desigual da neoliberalização» (HARVEY, 2007, p. 97), e, ainda, com a devida ponderação do alcance das ações educativas, pois a educação não é uma arma milagrosa para colocar ordem no mundo, nem mesmo com a utilização massiva, correta e ética das novas tecnologias da informação e da comunicação, como realmente pode acontecer na sequência do empoderamento comunicacional digital dos alunos, isto é, do reforço da sua potentia comunicativa, vale dizer, da sua capacidade de interagir dialogicamente com o entorno, que é para onde se remete, neste texto, essa ideia do empoderamento como reforço de poderes ou capacidades. Ou seja, a potentia como origem etimológica 
privilegiada da representação do poder (capacidade de atuar no mundo para eventualmente o transformar), o «poder para», segundo Steven Lukes (2007, p.76), e não o "poder sobre», a capacidade de controlar ou dominar algo ou alguém, cujo étimo é a potestas. Em vez do poder coercitivo, limitativo e controlador (potestas), o poder produtivo, gerador, criador, transformador, na linha etimológica latina da potentia, ou da puissance, como dizem os franceses.

Assim interpretado, o fortalecimento do poder, eidos e telos da ideia de empoderamento, pode-se traduzir na ativação de forças subjetivas e intersubjetivas de remodelação da realidade social no sentido de a orientar para mais justiça social, quer em termos de redistribuição de riqueza e rendimento mediante políticas fiscais e sociais, quer em termos de igualização de oportunidades de sucesso nas diferentes esferas sociais, inclusive na escola, através de medidas compensatórias ou de discriminação positiva, especialmente na direção dos mais atingidos por injustiças recorrentes ou «estruturais», como prefere Young (2011, p. 172)

A essa luz, ou com esse pano de fundo, quisemos mostrar, indicando pautas de desenvolvimento curricular, e tendo por referência a escola, que é possível alavancar o empoderamento político dos alunos e assim prepará-los para o enfrentamento dos problemas que hoje nos atormentam, desde a crise climática à crise da democracia, passando pelo escândalo do aprofundamento do fosso das desigualdades e dessa «insegurança existencial» (BAUMAN, 2016, p. 31) que assombra os nossos dias e corre o risco de nos paralisar diante das injustiças, das exclusões, das discriminações, dos modelos de desenvolvimento insustentáveis, das «elites predatórias» (SASSEN, 2015, p. 24) e do definhamento dos regimes democráticos (CASTELLS, 2017). O empoderamento político dos alunos, dos cidadãos do presente e do futuro, não é a varinha mágica que tudo resolve, pelo menos no imediato, mas contribui seguramente para colocar as questões no registro apropriado: o registro da intervenção e da decisão política.

\section{REFERÊNCIAS:}

APPADURAI, A. Condition de l'homme global. Paris: Payot, 2013.

AVENT, R. La riqueza de los humanos. El trabajo en el siglo XXI. Barcelona: Ariel, 2017.

BACQUÉ, M.; BIEWENER, C. L'empowerment: une pratique émancipatrice. Paris: La Découverte, 2013.

BAUMAN, Z. El arte de la vida. Barcelona: Paidós, 2009. 
BAUMAN, Z. Extraños llamando a la puerta. Barcelona: Paidós, 2016.

BAUMAN, Z. Retrotopía. Barcelona: Paidós, 2017.

BECK, U. A metamorfose do mundo. Lisboa: Edições 70, 2017.

BECK, U.; BECK-GERNSHEIM, E. La individualización. E1 individualismo institucionalizado y sus consecuencias sociales y políticas. Barcelona: Paidós, 2003.

BONNEUIL, C.; FRESSOZ, J. L'événement anthropocène. Paris: Seuil, 2013.

BROWN, W. El Pueblo sin atributos. La secreta revolución del neoliberalismo. Barcelona: Malpaso, 2016.

CALISKAN, K; CALLON, M. Economization, part 1: Shifting attention from the economy towards processes of economization. Economy and Society, v. 38, n. 3, ago, p. 369-398. 2009.

CALVÉS, A. "Empowerment": Généalogie d'un concept clé du discours contemporain sur le développement. Revue Tiers Monde, n. 200, p. 735-749. 2009.

CASTELLS, M. La Galáxia Internet. Reflexiones sobre Internet, empresa y sociedad. Barcelona: Plaza \& Janes Editores, 2001.

CASTELLS, M. Ruptura: la crisis de la democracia. Madrid: Alianza Editorial, 2017.

CHOMSKY, N.; POLYCHRONIOU, C. Otimismo e não desespero. Amadora: Elsinore, 2017.

DIGHE, A. Women's literacy and empowerment of women. In: MEDEL-AÑONUEVO, C. (ed.). Women, education and empowerment. Pathways towards autonomy. Hamburg: Unesco Institute for Education, 1995. p. 39-45.

FERNÁNDEZ LIRIA, C.; GARCÍA FERNÁNDEZ, O.; GALINDO FERRÁNDEZ, H. Escuela o barbarie. Entre el neoliberalismo salvaje y el delirio de la izquierda. Madrid: Akal, 2017.

FOUCAULT, M. Naissance de la biopolitique. Gallimard/Seuil, 2004.

FREIRE, P. Pedagogia do oprimido. Porto: Afrontamento, 1975.

FREIRE, P. Desmitificación de la concientización. In: TORRES, C. (ed.). Paulo Freire, educación y concientización. Salamanca: Sígueme, 1980. p. 60-72.

FREIRE, P. Pedagogia da autonomia. Saberes necessários à prática educativa. São Paulo: Paz e Terra, 1996.

FREIRE, P.; SHOR, I. Medo e ousadia. O cotidiano do professor. Rio de Janeiro: Paz e Terra, 1987.

FRIEDMAN, J. Empowerment. Uma política de desenvolvimento. Oeiras: Celta, 1996.

HARVEY, D. Breve historia del neoliberalismo. Madrid: Akal, 2007.

YOUNG, I. Responsabilidad por la justicia. Madrid: Morata, 2011.

LE BOSSÉ, Y. De l'habilitation au pouvoir d'agir: vers une appréhension plus circonscrite de la notion d'empowerment. Nouvelles Pratiques Sociales, v. 16, n. 2, p. 30-51. 2003. 
LOUÇÃ, F.; LOPES, J.; COSTA, J. Os burgueses. Quem são, como vivem, como mandam. Lisboa: Bertrand, 2014.

LUKES, S. El poder. Un enfoque radical. Madrid: Siglo XXI. 2007.

MARTÍN, X.; RUBIO, L. (coord.). Prácticas de ciudadanía. Diez experiencias de aprendizaje-servicio. Barcelona: Octaedro. 2010.

MBEMBE, A. Políticas da inimizade. Lisboa: Antígona, 2017.

NACHTWEY, O. Descivilização. Sobre tendências regressivas nas sociedades ocidentais. In: GEISELBERG, H. (ed.). O grande retrocesso. Lisboa: Objectiva, 2017. p. 205-220.

ORTOLL, E. Conceptos clave en alfabetización y exclusión digital. In: ORTOLL, E. (coord.). La alfabetización digital en los processos de inclusión social. Barcelona: UOC, 2007. p. 13-56.

PEREIRA, C. Appropriating 'gender' and 'empowerment': The resignification of feminist ideas in Nigeria's neoliberal reform program. IDS Bulletin, v. 39, n. 6, p. 42-45. 2008.

PHILLIPPI, A.; AVENDAÑO, C. Empoderamiento comunicacional: competencias narrativas de los sujetos. Comunicar, v. XVIII, n. 36, p. 61-68. 2011.

PINTO, C. "Uma prática de empowerment com adultos idosos". In: CARVALHO, M. (coord.). Serviço social no envelhecimento. Lisboa: Pactor, 2013, p. 49-65.

SASSEN, S. Expulsiones. Brutalidad y complexidad en la economía global. Buenos Aires/Madrid: Katz, 2015.

STREECK, W. Como terminará el capitalismo? Ensayos sobre un sistema en decadência. Madrid: Traficantes de Sueños, 2017.

TORRES SANTOMÉ, J. Políticas educativas y construcción de personalidades neoliberales y neocolonialistas. Madrid: Morata, 2017.

VENTOSA, V. Didáctica de la participación. Teoría, metodología y práctica. Madrid: Narcea, 2016.

WALLERSTEIN, I. Universalismo europeu. A retórica do poder. São Paulo: Boitempo Editorial, 2007.

Submetido: 20/07/2018

Aprovado: 09/10/2018

Contato:

Instituto de Educação (IE)

Universidade do Minho

Campus de Gualtar

Braga|Portugal

4710-057 